\title{
How remote are Vietnam's ethnic minorities? An analysis of spatial patterns of poverty and inequality
}

\author{
Michael Epprecht • Daniel Müller • \\ Nicholas Minot
}

Received: 29 September 2008 / Accepted: 18 September 2009 / Published online: 11 October 2009 (C) Springer-Verlag 2009

\begin{abstract}
This paper investigates whether physical accessibility or ethnicity is a stronger determinant of poverty in Vietnam. Spatially disaggregated welfare indexes for population subgroups show that overall inequality is shaped by an urban-rural welfare divide, closely followed in importance by sharp welfare differences between ethnic groups. Accessibility to urban areas is a weaker determinant of poverty. The findings have important implications for the targeting of rural development investments. Addressing the factors isolating ethnic minorities from the mainstream economy is likely to be a more useful strategy in reducing rural poverty and inequality than simple geographic targeting.
\end{abstract}

JEL Classification R200

\footnotetext{
M. Epprecht $(\varangle)$

Swiss National Centre of Competence in Research (NCCR) "North-South",

Centre for Development and Environment, Institute of Geography,

University of Berne, Hallerstrasse 10, 3012 Berne, Switzerland

e-mail: michael.epprecht@cde.unibe.ch; michael@epprecht.org

D. Müller

Leibniz Institute of Agricultural Development in Central and Eastern Europe (IAMO),

Theodor-Lieser-Str. 2, 06120 Halle (Saale), Germany

e-mail: mueller@iamo.de

D. Müller

Geomatics Lab, Geography Institute, Humboldt-Universität zu Berlin, Unter den Linden 6, 10099 Berlin, Germany

N. Minot

Markets, Trade, and Institutions Division, International Food Policy Research Institute (IFPRI),

2033 K Street, NW, Washington, DC, 20006-1002, USA

e-mail: n.minot@cgiar.org
} 


\section{Introduction}

Vietnam has achieved remarkable rates of economic growth since the "economic renovation' (doi moi) started in 1986. The incidence of poverty fell throughout the country, and increases in welfare disparities were smaller than generally anticipated (Haughton et al. 2001; Vietnam Development Report 2004 2003). Nevertheless, the gains in poverty reduction are far from uniformly distributed among population subgroups and across space. Specifically, there is strong evidence of increasing differences in welfare levels among different regions in Vietnam, between rural and urban households, as well as along ethnic lines.

Poverty and inequality levels differ sharply between rural and urban areas of the country (Glewwe 2004; Vietnam Development Report 2004 2003; Minot et al. 2006). Rural areas are typically poorer than the urban parts of Vietnam, whereas the level of inequality is generally higher in urban areas. Yet, rising inequality is of concern within urban areas and increasingly so within rural areas (Liu 2002; Gallup 2004; Glewwe 2004). To date, there is much debate about a growing rural-urban income divide in Vietnam.

In rural Vietnam, the distribution of poverty largely follows topography. Higher rates of poverty are found in mountainous upland areas than in the lowlands of the two large river basins (the Mekong Delta and the Red River Delta), the Southeast region and the coastal areas (Minot et al. 2006). Geographic remoteness is often cited as a major explanatory factor in upland poverty in Vietnam (for example, The Socialist Republic of Vietnam 2003; Baulch et al. 2007).

Geographic capital is generally thought to be one of the important determinants of well-being. Locational attributes in the form of soil quality, micro-climate, topography, access to roads, access to public services and access to political and economic centres are often correlated with income and expenditure levels (Gallup et al. 1999; Bigman and Deichmann 2000; Farrow et al. 2005). Upland areas tend to have more adverse conditions among various dimensions of geographic capital. Soils there may be less fertile, and the uneven terrain renders irrigation more costly. The lower potential for agricultural production leads to lower population densities, which in turn raises the per capita cost of providing roads, electricity and social services. Finally, the lower population density means that households live further from large urban centres, limiting opportunities for nonfarm employment and raising the cost of manufactured and imported goods. Ravallion and Jalan (1997) termed such geographic marginality a spatial poverty trap, referring to the disadvantageous geography that results in poor infrastructure and low returns to private endowments, effectively preventing people living in such places from escaping poverty.

Empirically, the spatial coincidence of poverty rates and physical remoteness is well established (Jalan and Ravallion 2002; Chomitz 2007). Although an adverse topography and distance per se cannot be altered by policies, one geographic factor that can, at least in the long run, be influenced by development policies and investment decisions is physical accessibility. ${ }^{1}$ Within the rural development discussion,

\footnotetext{
1 There are exceptions like investments in terraces, dam construction or soil fertility improvements that may change topographic and natural micro-conditions. However, these long-term investments are typically confined to small areas and not relevant for the analysis in this paper.
} 
Geertman and Reitsema van Eck (1995) assert that measures of physical accessibility can proxy rural deprivation. Poor physical accessibility implies higher transport costs for inputs and outputs and hampers access to services like education and extension. Consequently, investments in roads and other transportation infrastructure to improve accessibility are expected to contribute to poverty alleviation in remote areas (Jacoby 2000; van de Walle 2002).

Yet, it has been shown that physical accessibility is only a part of the story and other factors may matter in shaping poverty incidences (Minot et al. 2006). For example, poverty may often be associated with socio-cultural remoteness. This would imply that households may be equipped with comparable endowments of production factors, but they achieve systematically different outcomes that can be related to other household or group characteristics. In Vietnam, ethnicity is a main determinant of socio-cultural distance. Ethnicity defines, among other things, household and group characteristics such as language, religious affiliation and other cultural factors that may potentially influence the incidence of poverty (Baulch et al. 2007; van de Walle and Gunewardena 2001).

Finally, as in many countries, the incidence of poverty is typically higher among ethnic minorities than among the majority population of Vietnam (van de Walle and Gunewardena 2001; Fritzen 2002; Swinkels and Turk 2004; Baulch et al. 2007). ${ }^{2}$ Empirical findings show less development in areas inhabited by ethnic minority groups compared to the areas where the ethnic majority reside. Since the ethnic minorities are concentrated in the geographically remote upland areas, the question is whether upland populations are poor because they are remote or because they are minorities.

This paper therefore investigates the contribution of two important factors that influence the spatial patterns of rural poverty in Vietnam: physical accessibility and ethnicity. Specifically, we apply spatial regression analysis to examine the effect of accessibility and ethnicity on poverty at the commune level. The next section describes the data, methods and concepts used for the analysis. Section 3 presents the results of the descriptive analysis of spatial patterns of poverty in Vietnam, followed by a decomposition of overall and rural inequality. We then present the results of the spatial regression analysis that investigates the contributions of adverse geography, proxied by various measures of accessibility and of ethnicity to commune-level poverty. The paper concludes with a discussion of our key result and their implications for rural development policies in Vietnam.

\section{Data and methods}

\subsection{Poverty and inequality measurements}

We use in this analysis the most widely used measure of poverty, the incidence of poverty $\left(P_{0}\right)$, also called the poverty headcount or the poverty rate, which measures

\footnotetext{
2 In this analysis, we follow the common practice in Vietnam and refer to the ethnic majority population as those who belong to the Kinh or Hoa (ethnic Chinese) ethnic group, while all other ethnic groups make up the ethnic minority population.
} 
the share of the population below the poverty line. ${ }^{3} P_{0}$ is part of a class of poverty measures commonly referred to as the Foster-Greer-Thorbecke (FGT) measures of poverty that are defined as follows (Foster et al. 1984):

$$
P_{\alpha}=\frac{1}{N} \sum_{i=1}^{M}\left[\frac{z-y_{i}}{z}\right]^{\alpha}
$$

where $z$ is the poverty line, $y_{i}$ is the real per capita expenditure of person $i$ in a poor household, $N$ is the size of the total population, and $M$ is the number of individuals in poor households. $\alpha$ indicates the specific measure of poverty and describes the degree of aversion to poverty: a higher value of $\alpha$ indicates a higher weight given to the poorest households. If $\alpha=0$, Eq. (1) reduces to

$$
P_{0}=\frac{1}{N} \sum_{i=1}^{M}(1)=\frac{M}{N}
$$

which is the share of the total population below the poverty line $\left(P_{0}\right)$.

The inequality measure employed in this paper is the Theil $L$ index of inequality, ${ }^{4}$ which is part of a class of generalised entropy measures, known as $\operatorname{GE}(\alpha)$, where $\alpha$ indicates the specific member of the class. A higher $\alpha$ implies a greater sensitivity of the measure to differences in wealth nearer the top of the overall wealth distribution, and a smaller $\alpha$ indicates greater sensitivity to differences near the bottom of the distribution.

The generalised entropy measure of inequality GE(0) has the form (Theil 1967):

$$
\operatorname{GE}(0)=\frac{1}{N} \sum_{i=1}^{N} \ln \left(\frac{\bar{y}}{y_{i}}\right)
$$

where $y_{i}$ is the individual household per capita expenditure, $\bar{y}$ is the average per capita expenditure, and $N$ is the number of households. $\mathrm{GE}(0)$ is calculated in relation to the mean expenditure of each specific sub-population separately and is therefore a measure of relative inequality. GE(0) can range from 0 to infinity, with a higher $\mathrm{GE}(0)$ implying greater inequality.

We opted for this measure of inequality because a generalised entropy inequality index such as $\mathrm{GE}(0)$ can be decomposed for mutually exclusive population subgroups into a within component $\mathrm{GE}(0)_{w}$ of the population subgroup and a between component $\mathrm{GE}(0)_{b}$, which in sum make up the inequality of the total population:

\footnotetext{
3 Earlier research showed that other measures of poverty, such as the depth or the severity of poverty ( $P_{1}$ and $P_{2}$, respectively), are closely correlated to $P_{0}$ (Minot et al. 2006), and we would therefore expect to see very similar results when using different measures of poverty in the analysis.

4 We also calculated the Gini coefficient and GE1 (also called Theil $T$ index). The three measures are strong and positively correlated for all sub-populations used.
} 
$\mathrm{GE}(0)_{t}=\mathrm{GE}(0)_{w}+\mathrm{GE}(0)_{b}$ (Anand 1983). The within-component takes the following form:

$$
\mathrm{GE}(0)_{W}=\sum_{k} \frac{N_{k}}{N} \mathrm{GE}(0)_{k}
$$

and the between-component can be written as:

$$
\mathrm{GE}(0)_{B}=\frac{1}{N} \sum_{i=1}^{N} \ln \left(\frac{\bar{y}}{\bar{y}_{k}}\right)
$$

with $k$ subgroups of $N_{k}$ households, the subgroup inequality index $\operatorname{GE}(0)_{k}$ and $\bar{y}_{k}$ as the mean expenditure of the population subgroup.

The share of the between-group component of total inequality, however, is often surprisingly small, and some scholars recently argued that the relatively small share of between-group inequality compared to the within-group inequality can be misleading (e.g. Kanbur 2000; Elbers et al. 2005). Elbers et al. (2005) proposed an alternative measure of the between-component, where the between inequality $\operatorname{GE}(0)_{b}$ is compared to a hypothetical maximum possible between-group inequality, rather than to the total inequality. Following Elbers et al. (2005), we calculate the maximum possible between-group inequality by redistributing households among the subgroups while keeping constant the size and number of subgroups, the ranking of mean per capita expenditure across subgroups and the total expenditure. More specifically, we maximise sub-group inequality by sorting the households by per capita expenditure, assigning the poorest households to the subgroup with the lowest mean per capita expenditure, the subsequent households to the next poorest subgroup and so on, until the richest households are assigned to the subgroup with the highest mean per capita expenditure. The observed between-group inequality component is then normalised by the calculated maximum possible between-group inequality. By definition, the alternative between-group measure of inequality is always greater (or in the most extreme case equal) than the conventional one.

\subsection{Household welfare data}

Both measures of poverty and inequality are calculated using household per capita expenditure estimates in relation to the national poverty line. ${ }^{5}$ The expenditure data are based on estimates combining information from the 1998 Vietnam Living Standards Survey (VLSS) and from a 33\% sample of the 1999 Vietnam Population and Housing Census (PHC) using small-area estimation techniques. The methods, data and results of the small-area estimation have been discussed in detail in earlier work (Minot et al. 2006). We re-estimated the same models using the same input data, but omitting the independent variable on ethnicity of the head of household, in order to

5 The 1999 national poverty line in Vietnam was set at an annual per capita consumption of $1,789,871$ VND, which was equal to approximately 128 USD. 
avoid getting spurious results in our subsequent analysis on the relationship between poverty incidence and ethnicity. The results from this model-household per capita expenditure estimates as well as their standard errors - very closely matched those of the original model described in Minot et al. (2006). Omitting the ethnicity variable did not have any noticeable effect on the model performance. This is not surprising, given that this variable was found to be a surprisingly weak predictor in the original model after controlling for other variables (Minot et al. 2006).

The entire data set includes welfare estimates for all of Vietnam's 10,479 communes with a total population of over 76 million, of which 8,916 are rural communes, home to over 58 million people. The average rural commune has a population of over 6,500 people, while the average population of the urban communes is over 11,500. With an average area of about $35 \mathrm{~km}^{2}$, the rural communes are considerably larger than the urban communes, which have an average area of $7.5 \mathrm{~km}^{2}$. Almost half of all the rural communes are located in mountainous areas, often with difficult physical accessibility conditions. Those communes account for about three quarters of the total rural area of the country. The majority of the population (over $86 \%$ ) belong to the ethnic Kinh (ethnic Vietnamese), which dominate the urban population, the lowland areas and many of the upland valleys. The uplands, in contrast, are inhabited mainly by a multitude of ethnic minority groups.

\subsection{Physical and socio-cultural accessibility}

The spatial dimension of poverty in Vietnam is often associated with remoteness. A central argument in the literature is that " $\mathrm{t}]$ he poorest people live in remote villages, often in upland areas, with limited access to transportation and social interaction" (IFAD 2005). The fact that remoteness is a major factor in perpetuating poverty is also prominently mentioned in international poverty analysis reports, as well as for instance in the national Comprehensive Poverty Reduction and Growth Strategy (for example, Socialist Republic of Vietnam 2003; Centre for International Economics 2002). What exactly 'remoteness' refers to is, however, often less clear.

The concept of accessibility in space, which can be considered as the inverse of remoteness, has been described for instance by Deichmann (1997) as the ability for interactions to occur between locations. Within such a concept, 'distance' is a major component. However, the distance between two locations may differ greatly, depending on the measurement used: straight line distance, travel distance, travel time, monetary travel cost, or some measure of socio-cultural distance (for example, Akerlof 1997; Conley and Topa 2002). While the first four measures are relatively easy to quantify, the last one is less so.

In this paper, the analysis focuses on two distance measures. First, travel time from the nearest urban area is used as a measure of physical distance that is relevant to rural dwellers in order to access markets and services. We refer to this dimension as physical accessibility and (its inverse) physical remoteness. The calculations of the hypothetical travel time take into account the assumed best available means of transport, the transport network, road quality, terrain and land cover. We use three measures of physical accessibility: (1) travel time to any area classified as urban; (2) travel time 
to the nearest urban centres with a population of 100,000 or more; and (3) travel time to the nearest of the two cities with a population of over 1 million (Ho Chi Minh City and Hanoi). The assumption behind this choice is that access to urban areas provides benefits in the form of remunerative off-farm employment, access to markets for agricultural outputs and inputs, markets for consumer goods and public services such as hospitals and educational facilities. Moreover, the size of urban centres is expected to proxy the diversity, size and quality of markets and services available in an urban area. All calculations of physical accessibility are carried out using the geographic information systems (GIS) software Arc/INFO with the software's 'costdistance' function and result in one map for each measure of physical accessibility.

Second, we use in the regression analysis ethnicity, with ethnic Vietnamese as reference, as well as the percentage of the commune population of 15 years and older that can read and write Vietnamese, as a proxy for socio-cultural distance. The official language in the Vietnamese education system is Vietnamese, and knowledge of the language is essential for ethnic minorities to communicate with service providers and potential commercial partners, who regularly are ethnic Kinh.

\subsection{Spatial statistical analysis}

Poverty often occurs in geographic clusters, and poverty measures typically show positive spatial autocorrelation. The degree of spatial autocorrelation may indicate the degree of clustering and therefore carries substantive information. For continuous variables, spatial autocorrelation can be quantified using the Moran's I statistic. The Moran's $I$ is a measure of two-dimensional spatial autocorrelation, similar to the Durbin-Watson test for univariate time series correlation (Anselin 1988b). The Moran's $I$ takes the form

$$
I=\frac{\sum_{i=1}^{N} \sum_{j=1}^{N, j \neq i} w_{i j}\left(x_{i}-\mu\right)\left(x_{j}-\mu\right)}{S \sum_{i=1}^{N}\left(x_{i}-\mu\right)^{2}}
$$

where $N$ is the number of observations, $\mu$ is the mean of variable $x, w_{i j}$ is the spatial weight matrix reflecting the proximity between location $i$ and $j$, and $S$ is a standardisation factor equal to the sum of all elements in the spatial weight matrix $W$. Therefore, $W$ defines the spatial structure for the locations that are included in the calculation of the Moran's $I$.

Spatial autocorrelation leads to biased and inconsistent estimators, which needs to be taken into account in regression-based estimation procedures (Anselin 1988b). There are two types of spatial dependencies: the spatial lag dependency, which occurs if the dependent variable in one location is directly influenced by the dependent variable in nearby locations, and the spatial error dependency, which refers to a situation in which the error term in one location is correlated with the error terms in nearby locations. The latter occurs if there are variables that have an effect on the dependent variable and are spatially correlated, but are not included in the regression model. 
The spatial lag model can be written as:

$$
y_{i}=\rho \sum_{j \neq i} w_{i j} y_{j}+X_{i} \beta+\varepsilon_{i}
$$

while the spatial error model takes the following form:

$$
y_{i}=X_{i} \beta+\lambda \sum_{j \neq i} w_{i j} \varepsilon_{j}+\varepsilon_{i}
$$

where $y_{i}$ is the dependent variable in location, $i, y_{j}$ the dependent variable at location, $j, \rho$ the spatial autoregressive coefficient of the spatial lag model, $\lambda$ the spatial autoregressive coefficient of the spatial error model, $w_{i j}$ the spatial weight reflecting the proximity of $i$ and $j, X_{i}$ a matrix of explanatory variables, $\beta$ a vector of coefficients, and $\varepsilon_{i}$ the error term at location $i$.

A Lagrange multiplier (LM) test is used to test the statistical significance of $\rho$ and $\lambda$, respectively. The LM test indicates which of the two models is more appropriate. Monte Carlo studies confirm that the LM test provides a reasonably accurate way to distinguish between the two models (Anselin 1988a).

\section{Spatial patterns and determinants of poverty and inequality}

\subsection{Poverty and inequality}

Table 1 provides summary statistics of the key variables by urban and rural areas as well as by the eight main agro-ecological regions of Vietnam. The poverty incidence $\left(P_{0}\right)$ in Vietnam exhibits a strong geographic dimension (Fig. 1). While the overall incidence of poverty in Vietnam was $37 \%$ in 1999 , it tends to be considerably higher in remote upland areas of the Northeast, the Northwest, the North Central Coast along the border to Laos in the West and in the Central Highlands (Table 1 and Fig. 1). $P_{0}$ is lower than the national average in much of the lowland areas of the large river deltas. Inequality, measured as $\operatorname{GE}(0)$, was 0.205 for the entire country in 1999 , which is relatively low compared to other countries in similar states of development. Inequality exhibits less distinct spatial patterns, although rural upland areas tend to exhibit higher levels of inequality compared to the rural lowland (Table 1 and Fig. 1).

Welfare levels also differ greatly between urban and rural areas. Mean per capita expenditure in urban areas is more than twice as high as in rural areas, a fact reflected in sharply differing poverty rates: the urban poverty rate at national level was estimated at $12 \%$ while the rural poverty rate stood at $44 \%$. Estimated inequality in urban areas $(\mathrm{GE}(0)=0.207)$ was notably higher than in rural areas $(\mathrm{GE}(0)=0.134)$. Parts of these differences are probably caused by differences in levels of education and skills (particularly skills in non-farm economic activities). In addition, the costs of migration and the lack of information about jobs and housing may create barriers that consolidate the differences in urban and rural living standards. Moreover, Vietnamese policies tend to restrict the flow of rural-to-urban migration (Anh et al. 2003; Waddington 2003), 
Table 1 Summary statistics of key variables

\begin{tabular}{|c|c|c|c|c|c|c|c|c|c|c|c|c|}
\hline \multirow[t]{2}{*}{ Region } & \multicolumn{3}{|l|}{$P_{0}$} & \multicolumn{3}{|l|}{$\mathrm{GE}(0)$} & \multicolumn{3}{|c|}{ Ethnic minorities (\%) } & \multicolumn{3}{|c|}{$\begin{array}{l}\text { Mean travel time ( } \min \text {.) } \\
\text { to urban areas with } \\
\text { a population of over }\end{array}$} \\
\hline & Urban & Rural & Total & Urban & Rural & Total & Urban & Rural & Total & 1 & $100 \mathrm{k}$ & 1 mill. \\
\hline National & 11.6 & 44.3 & 36.6 & 0.207 & 0.134 & 0.205 & 0.9 & 11.8 & 12.7 & 40 & 147 & 320 \\
\hline RRD & 7.7 & 38.0 & 31.6 & 0.186 & 0.111 & 0.187 & 0.1 & 0.3 & 0.4 & 7 & 28 & 67 \\
\hline $\mathrm{NE}$ & 16.8 & 56.9 & 50.3 & 0.191 & 0.136 & 0.185 & 2.3 & 31.4 & 33.7 & 61 & 244 & 270 \\
\hline NW & 15.5 & 77.4 & 69.9 & 0.179 & 0.141 & 0.216 & 2.8 & 76.8 & 79.6 & 129 & 540 & 545 \\
\hline $\mathrm{NCC}$ & 16.0 & 50.6 & 46.3 & 0.199 & 0.122 & 0.165 & 0.2 & 10.4 & 10.6 & 39 & 103 & 383 \\
\hline SCC & 14.5 & 45.8 & 37.4 & 0.203 & 0.129 & 0.196 & 0.4 & 4.9 & 5.3 & 47 & 131 & 925 \\
\hline $\mathrm{CH}$ & 18.5 & 55.5 & 46.8 & 0.187 & 0.161 & 0.213 & 3.0 & 33.8 & 36.7 & 57 & 252 & 834 \\
\hline SE & 6.9 & 23.7 & 15.2 & 0.207 & 0.147 & 0.230 & 0.6 & 4.2 & 4.8 & 28 & 80 & 157 \\
\hline MRD & 17.7 & 39.6 & 35.8 & 0.217 & 0.125 & 0.168 & 0.7 & 5.8 & 6.5 & 13 & 45 & 159 \\
\hline
\end{tabular}

$R R D$ Red River Delta, $N E$ Northeast, $N W$ Northwest, $N C C$ North Central Coast, SCC South Central Coast, $C H$ Central Highlands, $S E$ Southeast, $M R D$ Mekong River Delta
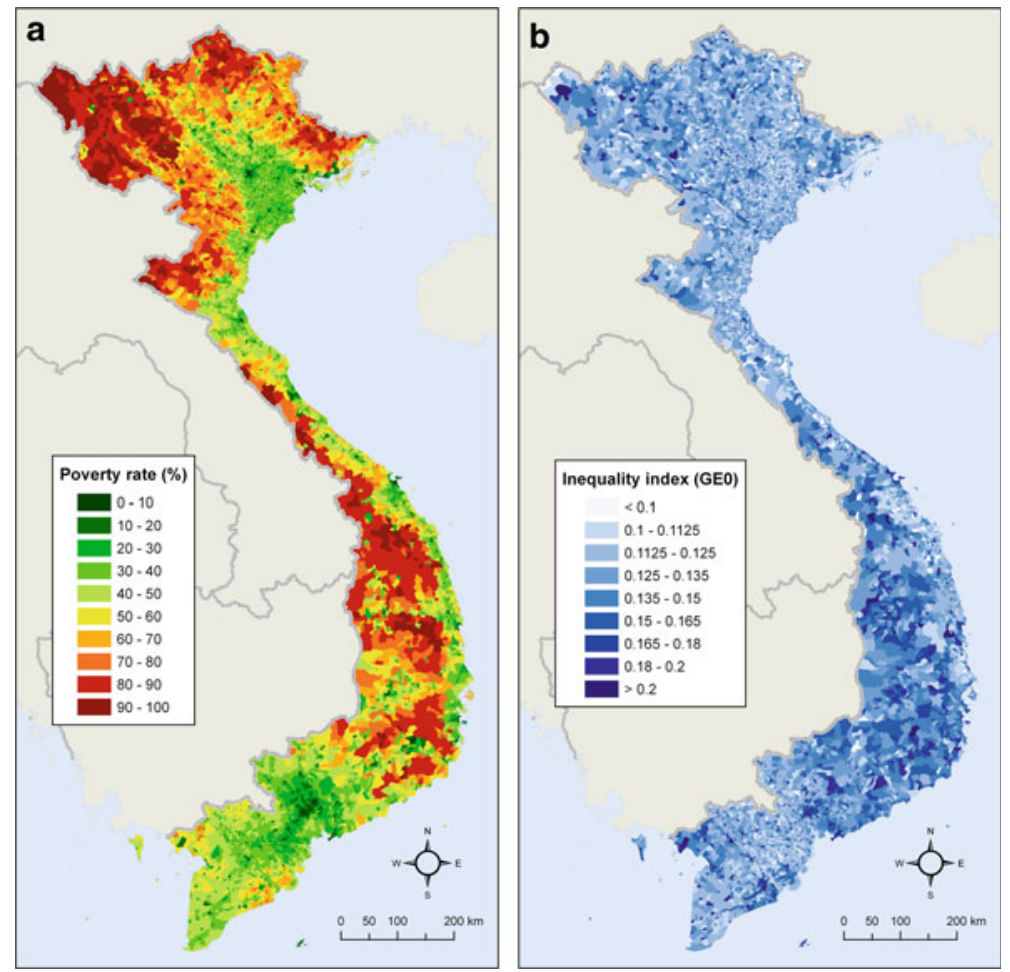

Fig. 1 The spatial distribution of poverty rate and inequality 
Table 2 Correlation matrix of key variables

\begin{tabular}{llllll}
\hline & GE(0) & $P_{0}$ & $\begin{array}{l}\text { Ethnic minority } \\
\text { share }\end{array}$ & $\begin{array}{l}\text { Travel time to } \\
\text { urban areas }\end{array}$ & $\begin{array}{l}\text { Travel time to } \\
\text { urban areas }>100 \mathrm{k}\end{array}$ \\
\hline$P_{0}$ & 0.063 & 1 & & & \\
$\begin{array}{l}\text { Ethnic minority share } \\
\text { in commune }\end{array}$ & 0.156 & 0.817 & 1 & 1 & \\
$\begin{array}{l}\text { Travel time to urban } \\
\text { areas }\end{array}$ & 0.079 & 0.684 & 0.677 & 0.767 & \\
$\begin{array}{l}\text { Travel time to urban } \\
\text { areas with a } \\
\text { population }>100 \mathrm{k}\end{array}$ & 0.079 & 0.691 & 0.723 & 0.615 \\
$\begin{array}{l}\text { Travel time to urban } \\
\text { areas with a } \\
\text { population }\end{array}$ & 0.133 & 0.547 & 0.442 & & \\
$>1$ million & & & & & \\
\hline
\end{tabular}

which probably exacerbates rural-urban income differences (Anh 1999). To a large extent, Vietnam's ethnic minority population is spatially segregated from the majority, being concentrated in the Northeast, the Northwest, the Central Highlands and in the upland areas of other regions. These are also the regions with the highest incidence of poverty in the country (Vietnam Development Report 2004 2003; Swinkels and Turk 2004; Minot et al. 2006). At the national level, 74\% of the ethnic minority population is below the poverty line, compared to $30 \%$ of the majority Kinh. In rural areas, these figures are $77 \%$ and $37 \%$, respectively. With a $\mathrm{GE}(0)$ of 0.118 , both the rural majority and the minority populations have the same, rather low, degree of inequality within each group. ${ }^{6}$

Table 2 provides an overview of the pair-wise correlation of these key variables in rural areas to better illustrate the strong relationship between several of the key variables. Table 2 highlights a strong positive and significant correlation between the share of the ethnic minority population in a commune and the three physical accessibility measures as well as with $P_{0}$. Likewise, Table 2 illustrates similar associations in terms of strengths and significance between $\mathrm{P} 0$ and the three accessibility measures. Again, it is unclear if ethnicity is the dominant determinant of poverty or if adverse accessibility is largely to blame for above-average poverty incidences.

To explore the spatial patterns of poverty for ethnic minorities and majorities, we map commune-level welfare measures for each ethnic subgroup separately. Communes with less than 30 households of the respective group are excluded. Figure 2 presents the poverty rates for the ethnic majority population on the left and for the minority population on the right. The discrepancies between the two maps are striking: In all parts of the country, the poverty rates of the ethnic minority population are distinctively higher than those of the ethnic majority population. This pattern holds for communes where the Kinh are the majority and where ethnic minorities are the majority. It applies

\footnotetext{
6 We also analysed the poverty rates and inequality for each of the eight ethno-linguistic groups, as well as for each of the 54 ethnic groups. The poverty rates were consistently much higher for all ethnic minority groups compared to the ethnic majority, although the inequality levels varied among the different ethnic groups.
} 

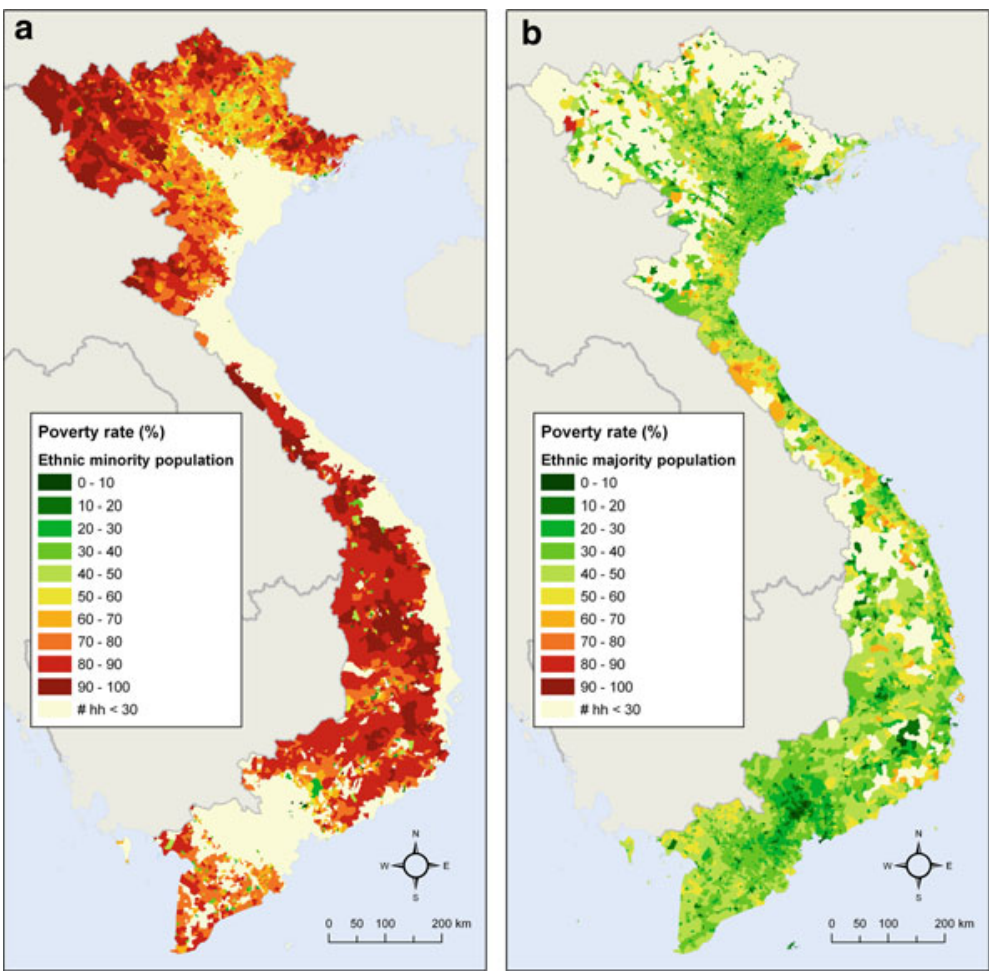

Fig. 2 The spatial distribution of poverty rate for ethnic subgroups

to remote areas as well as to places that are better accessible. Figure 2 also explains part of the inequality patterns from Fig. 1 that follow the spatial distribution of the poorer ethnic minority population relative to the better-off majority population.

\subsection{Inequalities by population subgroups}

We now decompose overall inequality into the within- and between-group component of the urban and rural sub-populations. We also decompose rural inequality by ethnicity and by geographic administrative units. Because ethnic minorities are poorer than the Kinh majority and because both groups exhibit relatively low internal inequality, one would expect that inequality within the ethnic groups contribute much less to overall inequality than the observed welfare differences between the two population groups.

Yet, the results indicate that only $12 \%$ of overall rural inequality are due to inequality between the two ethnic groups, whereas $88 \%$ are due to inequality within the two groups in rural areas (Table 3). This is consistent with the findings presented in other studies (for example, Anand 1983; Cowell and Jenkins 1995; Kanbur 2002). The between-group component is often unexpectedly small and in the range of around $15 \%$ (Kanbur 2002), because it has few observations (two in our case, the mean per capita 
Table 3 Inequality (GE(0)) decomposition by population sub-groups

\begin{tabular}{lclc}
\hline Sub-population (number of groups) & Between & \% Of max. between & Within \\
\hline Region (8) & 4 & 10 & 96 \\
Province (62) & 8 & 16 & 92 \\
District (614) & 12 & 25 & 88 \\
Commune (10,479) & 14 & 32 & 86 \\
Urban-rural (2) & 25 & 62 & 75 \\
Ethnic minority (2) & 12 & 62 & 88 \\
Ethno-linguistic (8) & 11 & 69 & 89 \\
Ethnic group (54) & 13 & 73 & 87 \\
\hline
\end{tabular}

expenditure of the ethnic minorities and of the majorities) compared to the 'within' component that contains all the respective households. As the per capita expenditures across households within each group have a larger range than the means of each group, the resulting within-group inequality is always larger than the between-group inequality (Kanbur 2002).

We therefore calculate the observed between-component as a share of the maximum possible between-component, given the existing overall expenditure distribution (see Sect. 2.1). In order to allow for a better interpretation of the decompositions, we present the between- and within-shares as well as the alternative between shares for the sub-populations defined by the three administrative units, by urban and rural and by ethnicity.

The alternative measure shows that the between-group inequality is a large percentage of the maximum possible between-group inequality in the case of ethnicity and the urban-rural decompositions. This percentage is much smaller for the geographic groupings, where the between-group inequality is generally below $50 \%$ of the maximum possible (Table 3 ).

Table 3 illustrates that the observed inequality between urban and rural areas accounts for $62 \%$ of the maximum possible inequality between the two population subgroups. It reaches a similarly high proportion in the ethnic minority-ethnic majority decomposition. These shares are much higher than the conventional between-group shares (25\% and 10\%, respectively) and indicate strong inequality along major ethnic lines. The proportions of the maximum attainable between-group components are even higher if decomposed by all 54 ethnic groups where the between-group inequality reaches almost three quarter of the maximum possible level, while decomposition along the eight ethno-linguistic groups resulted in $69 \%$ of the maximum possible between-group inequality. The inequality between administrative areas contributes considerably less to overall rural inequality (Table 3).

\subsection{Determinants of poverty and inequality}

We have shown that poverty incidences closely match the spatial distribution of the ethnic minority population and the spatial distribution of remoteness (or physical 

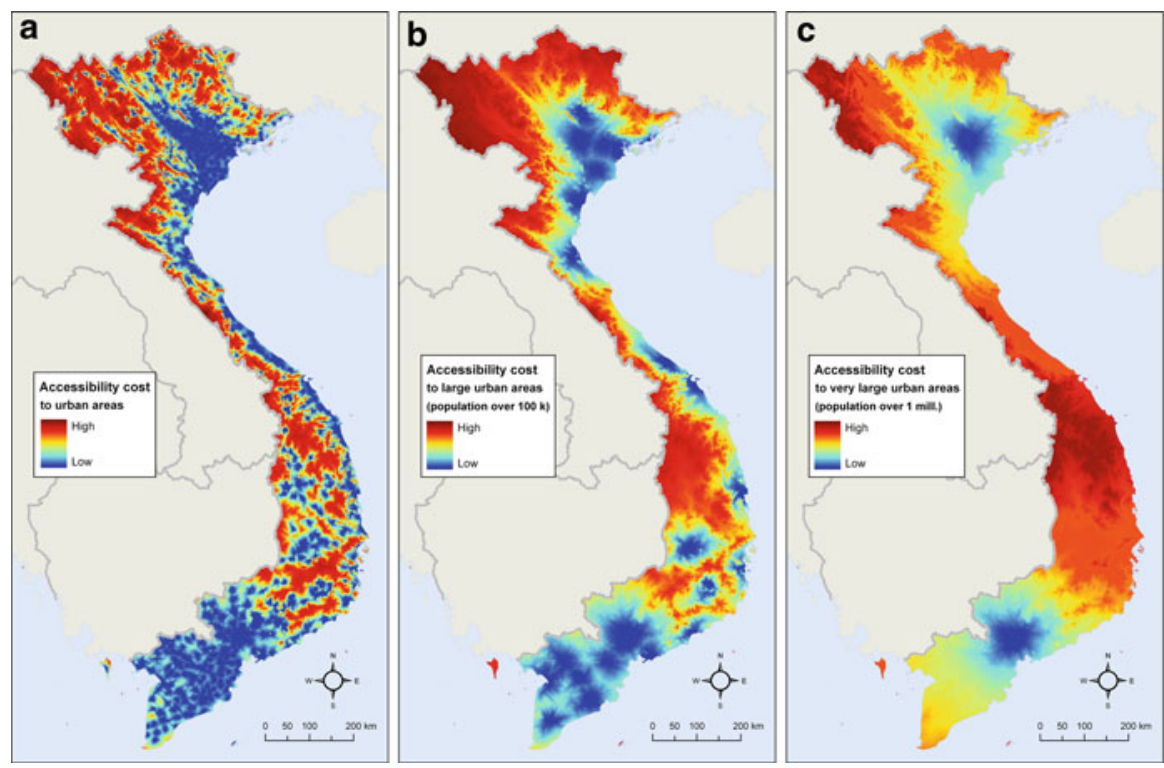

Fig. 3 The spatial distribution of local, regional, and global measures of accessibility

accessibility) (Fig. 3). But is it more important for household welfare where a household lives or whether a household belongs to an ethnic minority group? To answer this question, a regression model was estimated with the communal poverty estimates as the dependent variable. The estimation is restricted to the 8,916 rural communes since the accessibility indicators have little meaning in urban areas and since relatively few ethnic minority households reside in urban areas.

The Moran's $I$ for rural commune-level poverty rates is 0.85 , indicating high positive spatial autocorrelation (see also Fig. 1). This implies that high (low) poverty rates in one commune suggest that surrounding locations are likely to have high (low) rates as well. Spatial autocorrelation implies the violation of the independence of observations, and ordinary least squares (OLS) will yield biased and inconsistent estimates. Therefore, we apply spatial regressions techniques. This requires defining a spatial weight matrix $W_{i j}$ that describes the neighbourhood structure of the observations (see Sect. 2.4). However, the choice of $W_{i j}$ is based partly on the researcher's insights. We therefore test several configurations for $W_{i j}$ ranging from contiguity to distancebased weights to evaluate the robustness of the results. Furthermore, we test the sensitivity of the results to higher-order spatial autocorrelation by using first- to fourth-order spatial contiguity matrices (Bell and Bockstael 2000; Cohen and Paul 2007). The LM tests were robust to the choice of the weighting scheme and the subsequent regression results were very similar in coefficient signs, strengths and model fit. Assuming independent residuals, we select the weighting scheme that resulted in the lowest Akaike Information Criterion (AIC) for the spatial regression model (Buckland et al. 1997; 
Table 4 Diagnostic tests for spatial dependencies in rural poverty

\begin{tabular}{lcc}
\hline $\begin{array}{l}\text { OLS model } \\
\text { Test }\end{array}$ & Value & Probability \\
\hline Moran's I & 0.85 & \\
Robust LM (error) & $2,426.588$ & 0.00 \\
Robust LM (lag) & 28.577 & 0.00 \\
\hline
\end{tabular}

Zucchini 2000). We obtained the lowest AIC for first-order queen contiguity weights, which in turn was used for all subsequent calculations. ${ }^{7}$

We test the significance of spatial lag and spatial error dependencies with a LM test based on an OLS (Table 4). The results indicate that both types of spatial dependency are statistically significant. However, the much larger LM in the spatial error model suggests that error dependency is likely to be stronger, and we proceed with the spatial error model.

The spatial error model is estimated using maximum likelihood estimation. We use the three different accessibility measures along with their squared terms as covariates to test whether poverty rates exhibit a non-linear relationship with accessibility. Intuitively, we expect the effect of an increase in travel time from 0 to 1 hour to have a larger effect on poverty than an increase from 10 to 11 hours, which implies non-linearity in the relationship.

We also include the share of the commune population of at least 15 years of age that can read and write Vietnamese to control for basic educational aspects; furthermore, this variable can also be seen as a proxy for socio-cultural distance from the ethnic majority. ${ }^{8}$ We include the number of different ethnic groups per commune as a measure of ethnic fragmentation within each commune. ${ }^{9}$ As the main measure of socio-cultural distance from the ethnic majority, we include 53 dummy variables for each ethnic group (with the ethnic Vietnamese (Kinh) as the reference) that makes up the majority of the households within a commune. A covariate measuring the share of the population of the largest ethnic group within a commune captures ethnic fragmentation and the communal socio-cultural setting. Finally, we control for the basic demographic characteristics of the communes by including age groups. All covariates are checked for multicollinearity. We detected no multicollinearity in the data above 0.7 , except for the two first accessibility variables which had a higher correlation coefficient (0.76). All covariates are standardised to enable a consistent comparison of the influence and strength of the coefficients.

\footnotetext{
7 Queen contiguity is defined in analogy to the game of chess. An observation is contiguous in the queen case, if it shares a common border or vertex with the observation of interest. First-order queen contiguity weights include all immediate neighbours that share a common border or vertex with the observation of interest (Anselin 1988a,b).

8 There is no information in the census data on whether people speak and understand Vietnamese, which could serve as a good measure of socio-cultural distance to the ethnic majority of the country. However, the issue whether people are able to read and write Vietnamese serves as an adequate substitute proxy for how well ethnic minority people are integrated into the country's mainstream socio-economic life.

9 We calculate the number of ethnic groups per commune based on the ethnicity of the head of household, taking into account any ethnic group that make up at least $2 \%$ of the households in the commune.
} 
Table 5 presents the results of the spatial error model. As expected, the relationship between accessibility and poverty depends strongly on the measurement of accessibility. People tend to be poorer the further they are away from urban areas, indicated by a strong positive coefficient. The relationship between poverty and access to the larger cities with a population of above 100,000 inhabitants also indicates the importance of access to regional towns for alleviating poverty, although the variable explains only half as much of the variation in poverty as the access to urban areas. Remoteness defined as travel time to the two major cities of at least 1 million inhabitants is statistically not significantly related to poverty. The quadratic terms are significant for access to urban areas as well as for access to major metropolitan areas, although with relatively small predictive power. The results of the quadratic terms of the physical accessibility measures suggest that poverty continues to rise with travel time to the different types of urban areas throughout the observed range, ${ }^{10}$ although with diminishing rates further away from the urban areas.

The coefficients for the percentage of the commune population from the largest ethnic group and for the number of different ethnic groups per commune both indicate that ethnically more homogenous communes tend to be less poor. With the exception of the Hoa group (ethnic Chinese), which are typically not classified as an ethnic minority group (Baulch et al. 2007), the coefficients for all ethnic minority groups are positive and statistically significant except for two small minority groups (La $\mathrm{Hu}$ and $\mathrm{Pa}$ Then). All these groups are distinctively poorer than the ethnic majority group, even after controlling for aspects of physical remoteness, literacy and demographic characteristics. The literacy rate of the communal population over 14 years of age is negatively correlated with the communal poverty rate, also after controlling for ethnicity. ${ }^{11}$ While the coefficients of the individual ethnic groups are considerably weaker than the coefficient for urban access, the ethnicity coefficients together are almost one-third stronger than the physical accessibility coefficients together. ${ }^{12}$ In other words, remoteness does have a strong influence on rural wellbeing, but ethnicity is considerably more important in determining household welfare.

\section{Discussion and conclusions}

This paper examines the relative contributions of remoteness and ethnicity on rural poverty in Vietnam. Specifically, we assess whether the ethnic minority population of Vietnam is poorer than the majority population because they are ethnic minorities or

\footnotetext{
10 The travel measure was not calculated in metric units but is a relative measure of travel time to towns. The range of the standardised travel time extends from -1 to 1 . For all three travel-time variables, the model implies that poverty continues to rise as travel-time to urban areas increases, throughout the observed range of travel-time. In other words, the maximum of the quadratic function occurs outside the observed range.

11 Many of the smaller ethnic groups, whose coefficients are not or not very significant, have very low literacy rates (for example, the La Hu have the lowest literacy rate among all ethnic groups with $10 \%$ ), so that much of the relationship with poverty may have been picked-up by the literacy coefficient.

12 A similar model, using one variable describing the ethnic minority status instead of the individual ethnicity dummy variables, produced similar results. Furthermore, our tests showed that the inclusion of several additional physical accessibility variables in the regression model did not significantly increase the total strength of the physical accessibility coefficients.
} 
Table 5 Influence of accessibility and ethnicity on rural poverty rates

\begin{tabular}{|c|c|c|}
\hline $\begin{array}{l}\text { Pseudo } R^{2} \\
\text { Log likelihood } \\
\text { Variable }\end{array}$ & $\begin{array}{c}0.93 \\
13,924.259 \\
\text { Coefficient }\end{array}$ & $z$ \\
\hline Proportion of population $<6$ years old & 0.2048 & $35.54^{* * *}$ \\
\hline Proportion of population 6-15 years old & 0.2115 & $33.01^{* * *}$ \\
\hline Proportion of population $46-60$ years old & -0.0177 & $-1.89^{*}$ \\
\hline Proportion of population $>60$ years old & 0.0132 & 1.47 \\
\hline Travel time to urban areas & 0.0989 & $18.11^{* * *}$ \\
\hline Travel time to urban areas $>100$ thousand & 0.0527 & $6.52^{* * *}$ \\
\hline Travel time to urban areas $>1$ million & 0.0123 & 1.49 \\
\hline Travel time to urban areas sqd & -0.0066 & $-6.00^{* * *}$ \\
\hline Travel time to urban areas $>100$ thousand sqd & 0.0009 & 0.36 \\
\hline Travel time to urban areas $>1$ million sqd & -0.0061 & $-2.19^{* *}$ \\
\hline Literacy rate of population 15 years and over & -0.0561 & $-35.39^{* * *}$ \\
\hline Proportion of population of main ethnic group & -0.0082 & $-8.16^{* * *}$ \\
\hline Number of different ethnic groups in commune & 0.0042 & $2.58^{* *}$ \\
\hline Ba na ethnic group & 0.0102 & $14.98^{* * *}$ \\
\hline Bru Van Kieu ethnic group & 0.0057 & $8.71^{* * *}$ \\
\hline Cham ethnic group & 0.0038 & $7.33^{* * *}$ \\
\hline Chu ru ethnic group & 0.0010 & $2.24^{* *}$ \\
\hline Chut ethnic group & 0.0020 & $4.48^{* * *}$ \\
\hline Co ethnic group & 0.0061 & $7.47^{* * *}$ \\
\hline Co Lao ethnic group & 0.0008 & $1.79^{*}$ \\
\hline Co ho ethnic group & 0.0054 & $9.17^{* * *}$ \\
\hline Co tu ethnic group & 0.0081 & $8.77^{* * *}$ \\
\hline Cong ethnic group & 0.0010 & $2.20^{* *}$ \\
\hline Dao ethnic group & 0.0096 & $13.79^{* * *}$ \\
\hline E de ethnic group & 0.0056 & $10.66^{* * *}$ \\
\hline Gia rai ethnic group & 0.0088 & $12.66^{* * *}$ \\
\hline Giay ethnic group & 0.0034 & $6.82^{* * *}$ \\
\hline Gie Trieng ethnic group & 0.0041 & $5.33^{* * *}$ \\
\hline Ha Nhi ethnic group & 0.0026 & $4.43^{* * *}$ \\
\hline Hmong ethnic group & 0.0086 & $9.01^{* * *}$ \\
\hline Hoa ethnic group & -0.0021 & $-1.97^{* *}$ \\
\hline Hre ethnic group & 0.0114 & $12.81^{* * *}$ \\
\hline Kho me & 0.0064 & $10.10^{* * *}$ \\
\hline Kho mu ethnic group & 0.0036 & $6.73^{* * *}$ \\
\hline Kinh ethnic group & reference & \\
\hline La Chi ethnic group & 0.0023 & $3.51^{* * *}$ \\
\hline La Hu ethnic group & 0.0005 & 0.68 \\
\hline Lao ethnic group & 0.0021 & $4.53^{* * *}$ \\
\hline Lu ethnic group & 0.0015 & $3.08^{* * *}$ \\
\hline
\end{tabular}


Table 5 continued

\begin{tabular}{lcc}
\hline Variable & Coefficient & $z$ \\
\hline Ma ethnic group & 0.0031 & $5.33^{* * *}$ \\
Mnong ethnic group & 0.0054 & $8.77^{* * *}$ \\
Muong ethnic group & 0.0226 & $25.97^{* * *}$ \\
Nung ethnic group & 0.0157 & $19.70^{* * *}$ \\
Pa Then ethnic group & 0.0004 & 0.84 \\
Phu La ethnic group & 0.0020 & $4.30^{* * *}$ \\
Ra glai ethnic group & 0.0065 & $9.34^{* * *}$ \\
San Chay ethnic group & 0.0042 & $8.65^{* * *}$ \\
San Diu ethnic group & 0.0019 & $4.09^{* * *}$ \\
Ta oi ethnic group & 0.0055 & $7.32^{* * *}$ \\
Tay ethnic group & 0.0188 & $19.91^{* * *}$ \\
Thai ethnic group & 0.0219 & $22.77^{* * *}$ \\
Tho ethnic group & 0.0027 & $5.60^{* * *}$ \\
Xinh mun ethnic group & 0.0010 & $1.81^{*}$ \\
Xo dang ethnic group & 0.0090 & $10.68^{* * *}$ \\
Xtieng ethnic group & 0.0014 & $3.01^{* * *}$ \\
CONSTANT & 0.3215 & $82.48^{* * *}$ \\
LAMBDA & 0.6997 & $74.29^{* * *}$ \\
\hline
\end{tabular}

Note. $*$ Coefficient is significant at the $10 \%$ level, $* *$ at the $5 \%$ level, and $* * *$ at the $1 \%$ level

because of their physical remoteness from population centres. We explore communal poverty estimates using mapping techniques, calculated and decomposed inequality measures for different segments of the population and applied spatial regression analyses to quantify the respective contributions of ethnicity and physical remoteness to rural poverty.

Our results show that rural poverty significantly increases with geographic remoteness, even after controlling for other factors such as ethnicity and education. Interestingly, accessibility to small urban centres is a much stronger predictor of poverty than accessibility to larger urban centres, indicating the importance of local infrastructures such as local markets, health care facilities, or schools for poverty reduction. The importance of local access in Vietnam has been confirmed by other studies (for example, van de Walle and Gunewardena 2001).

Overall inequality in Vietnam is not only shaped by the urban-rural divide, but also by substantial differences in living standards between the rural geographic centre and the periphery and between ethnic minorities and the ethnic majority population. The poverty rate among the ethnic minority population, for instance, is twice as high compared to the rate of the ethnic majority population. Higher levels of inequality found in large parts of the rural upland areas are therefore caused primarily by the spatial coexistence of significantly poorer ethnic minority people with the better-off ethnic majority population. 
Socio-cultural distances such as language barriers or cultural differences may be a more important barrier to poverty alleviation than physical remoteness. Language barriers, for instance, might prevent an ethnic minority family from completing the paper work required to obtain credit or from purchasing a needed drug at the pharmacy, even if the travel time to the bank branch or a pharmacy is minimal. Indeed, this is reflected in the coefficients of our regression analysis, in which ethnicity and illiteracy both strongly contribute to poverty in rural Vietnam, reflecting the socio-cultural distance to the majority group. The strong and negative coefficient for literacy indicates the importance of being able to read and write in Vietnamese for poverty reduction. It also points to possible additional socio-cultural distances beyond ethnicity. For example, ethnic minority households that better master the Vietnamese language tend to be better off, presumably because they have better access to information and services.

These findings have two main policy implications:

1. The targeting of anti-poverty policies and programs must account for ethnic composition in addition to physical remoteness - at least at commune level, but preferably at household level.

2. While programs to reduce remoteness (roads, telecommunications, provision of services in small towns) are important, it is at least as important to take steps to reduce socio-cultural distances, for example, though language training and the provision of legal documents local languages.

\section{Targeting of development efforts towards disadvantaged population groups}

Although some significant recent poverty alleviation programmes of the Government of Vietnam started to use ethnicity as a criterion to identify beneficiaries, present pro-poor development policies largely focus assistance to ethnic minority areas and not towards ethnic minority households (van de Walle and Gunewardena 2001; Baulch et al. 2007). Many poor ethnic minority households may reside in a commune dominated by better-off ethnic majority households, which leaves such a commune classified as non-poor and hence exclude its poor minority households from assistance. But if socio-cultural distances are in fact more relevant than geographic distances in shaping poverty incidence, development policies aimed at balancing welfare levels across the population require increased emphasis on the targeting of specific disadvantaged groups, such as ethnic minorities. Such targeted approaches need to account for the specific natural, physical and human endowments of an ethnic minority group, as well as the potential economic returns of specific intervention strategies to particular sub-populations. The targeting of specific disadvantaged groups in the population may prove to be a more efficient avenue towards improving living standards and reducing inequality. However, such strategies would necessitate sophisticated approaches that consider local socio-economic situation analysis and development planning sensitive to socio-cultural peculiarities.

Recent efforts in Vietnam as part of the on-going public administration reform and the 'rolling-out' of the Comprehensive Poverty Reduction and Growth Strategy (CPRGS) signal a shift in the planning process towards such a direction. But a lack of incentives at local decision-making levels to improve the situation of disadvantaged population segments along with a lack of the necessary capacities renders its implementation at the local level a big challenge. 


\section{Reducing socio-cultural distances}

Improving accessibility through the provision of infrastructural networks such as transportation systems, marketing information systems, healthcare, or education infrastructure and services are important tools in rural poverty alleviation. Given the empirical evidence presented in this paper, these approaches are effective in reducing poverty incidence in Vietnam, particularly when targeted towards ethnic minority areas. Nevertheless, investments for reducing socio-cultural distances through improved provision of services and information specific to the needs of ethnic minorities appear to be crucial for further poverty reductions and for mitigating growing socio-economic inequalities. Such strategies may include options of multilingual education, provision of services in multiple languages and campaigns to increase crosscultural understanding and tolerance. The potential of improved physical accessibility for poverty reduction can only fully be reaped when complemented with an improvement of social and cultural acceptance of disadvantaged population segments without eliminating the rich cultural diversity.

\section{References}

Akerlof AG (1997) Social distance and social decisions. Econometrica 65(5):1005-1028

Anand S (1983) Inequality and poverty in Malaysia. Oxford University Press, Oxford

Anh DN (1999) Rural-urban transition and the impacts of migration. Vietnam's Socio-economic Dev 20:63-72

Anh DN, Tacoli C, Thanh HX (2003) Migration in Vietnam: a review of information on current trends and patterns, and their policy implications. In: Paper presented at the regional conference on migration, development and pro-poor policy choices in Asia, 22-24 June 2003 in Dhaka, Bangladesh

Anselin L (1988a) Lagrange multiplier test diagnostics for spatial dependence and spatial heterogeneity. Geogr Anal 20:1-17

Anselin L (1988b) Spatial econometrics: methods and models. Kluwer Academic Publishers, Dordrecht

Baulch B, Chuyen TTK, Haughton D, Haughton J (2007) Ethnic minority development in Vietnam. J Dev Stud 43(7):1151-1176

Bell KP, Bockstael NE (2000) Applying the generalized moments estimation approach to spatial problems involving microlevel data. Rev Econ Stat 82(1):72-82

Bigman D, Deichmann U (2000) Spatial indicators of access and fairness for the location of public facilities. In: Bigman D, Fofack H (eds) Geographical targeting for poverty alleviation: methodology and applications. The World Bank, Washington, DC pp 181-206

Buckland ST, Burnham KP, Augustin NH (1997) Model selection: an integral part of inference. Biometrics 53(2):603-618

Centre for International Economics (2002) Vietnam poverty analysis. Prepared for the Australian Agency for International Development (AUSAID), Canberra and Sydney

Chomitz KM (2007) At loggerheads? Agricultural expansion, poverty reduction, and environment in the tropical forests. The World Bank, Washington, DC

Cohen JP, Paul CM (2007) The impacts of transportation infrastructure on property values: a higher-order spatial econometrics approach. J Reg Sci 47(3):457-478

Conley TG, Topa G (2002) Socio-economic distance and spatial patterns in unemployment. J Appl Econom 17(4):303-327

Cowell FA, Jenkins SP (1995) How much inequality can we explain? A methodology and an application to the United States. Econ J 105(429):421-430

Deichmann U (1997) Accessibility indicators in GIS. United Nations Statistics Division, Department for Economic and Policy Analysis, United Nations, New York

Elbers C, Lanjouw P, Mistiaen JA, Özler B (2005) Re-interpreting sub-group inequality decompositions. The World Bank, Washington, DC 
Farrow A, Larrea C, Hyman G, Lema G (2005) Exploring the spatial variation of food poverty in Ecuador. Food Policy 30:510-531

Foster J, Greer J, Thorbecke E (1984) A class of decomposable poverty measures. Econometrica 52:761-766

Fritzen S (2002) Growth, inequality and the future of poverty reduction in Vietnam. J Asian Econ 13:635-657

Gallup JL (2004) The wage labour market and inequality in Vietnam. In: Glewwe P, Agarwal N, Dollar D (eds) Economic growth, poverty, and household welfare in Vietnam. The World Bank, Washington, DC pp 53-93

Gallup JL, Sachs JD, Mellinger AD (1999) Geography and economic development. Int Reg Sci Rev 22:179-232

Geertman SCM, Reitsema van Eck JR (1995) GIS and models of accessibility potential: an application in planning. Int J Geogr Inf Syst 9:67-80

Glewwe P (2004) An overview of economic growth and household welfare in Vietnam in the 1990s. In: Glewwe P, Agarwal N, Dollar DEconomic growth, poverty, and household welfare in Vietnam. The World Bank, Washington, DC pp 1-26

Haughton D, Haughton J, Phong N (eds) (2001) Living standards during an economic boom. Statistical Publishing House, Hanoi

IFAD [International Fund for Agricultural Development] (2005) IFAD in Vietnam. Rome, Italy

Jacoby HG (2000) Access to markets and the benefits of rural roads. Econ J 110(456):713-737

Jalan J, Ravallion M (1997) Spatial poverty traps. Policy Research Working Paper Series 1862. The World Bank, Washington, DC

Jalan J, Ravallion M (2002) Geographic poverty traps? A micro model of consumption growth in rural China. J Appl Econom 17:329-346

Kanbur R (2000) Income distribution and development. In: Atkinson AB, Bourguignon F (eds) Handbook of income distribution. Elsevier, Amsterdam pp 791-842

Kanbur R (2002) Notes of the policy significance of inequality decompositions. Cornell University, Ithaca

Liu AYC (2002) Markets, inequality and poverty in Vietnam. Asian Econ J 15:217-235

Minot N, Baulch B, Epprecht M (2006) Poverty and inequality in Vietnam-spatial patterns and geographic determinants. IFPRI Research Report \#148. International Food Policy Research Institute, Washington, DC

Ravallion M, Jalan J (1997) Spatial poverty traps? The World Bank, Policy Research Working Paper Series No. 1862

Socialist Republic of Vietnam (2003) The Comprehensive Poverty Reduction and Growth Strategy (CPRGS). Hanoi, Vietnam

Swinkels R, Turk C (2004) Poverty and remote areas: evidence from new data and questions for the future. Background paper for the PAC conference, 24-26 November 2004. Hanoi, Vietnam

Theil H (1967) Economic and information theory. North Holland, Amsterdam

van de Walle D (2002) Choosing rural road investments to help reduce poverty. World Dev 30(4):575-589

van de Walle D, Gunewardena D (2001) Sources of ethnic inequality in Vietnam. J Dev Econ 65:177-207

Vietnam Development Report 2004 (2003) Poverty, Joint Donor Report to the Vietnam Consultative Group Meeting. Hanoi, 2-3 December 2003

Waddington C (2003) National policy and internal migration. In: Paper presented at the regional conference on migration, development and pro-poor policy choices in Asia. 22-24 June 2003 in Dhaka, Bangladesh

Zucchini W (2000) An introduction to model selection. J Math Psychol 44(1):41-61 